\title{
APPLICATION OF TAXONOMETRIC AND DECISION-MAKING METHODS TO DRAFTING SCENARIOS OF RURAL AREA DEVELOPMENT*
}

\author{
Wektor Adamus \\ Agricultural University of Cracow, \\ Department of Agricultural Economics and Organization \\ Al. Mickiewicza 21, 31-120 Kraków, Poland \\ Feliks Wysocki \\ Agricultural University of Poznan \\ Department of Food and Agricultural Economics \\ Division of Econometrics Finance and Accountancy \\ ul. Wojska Polskiego 28, 60-637 Poznan, Poland
}

\begin{abstract}
Keywords: AHP; rural areas; scenarios; decision-making; taxonometric methods

Empirical research conducted has confirmed the suitability of the proposed method for preparing rural area development scenarios. Taxonometric methods were used to develop a typological classification of powiats in the Wielkopolskie Voivodship, which is the basic premise for constructing development scenarios. Two methods turned out to be useful: selection of the most appropriate number of clusters using the Xie-Beni, Kosko and F\&H indices and the fuzzy clustering method based on the Dunn-Bezdek algorithm, which determined to what extent particular units (powiats) belong to each identified functional type. Types were identified on the basis of characteristic features identified using the test of mean differences in a population and in fuzzy clusters as well as the general, theoretical classification of rural areas adopted by OECD.
\end{abstract}

Saaty's analytic hierarchy process (AHP) method turned out to be a particularly suitable tool for building rural area development scenarios. It was applied to every sub-region in order to assess the intensity of economic activities which should be undertaken to support rural area development and select the most appropriate development scenario.

In the first sub-region, the one best developed in functional terms, the industry and service scenario should be implemented (importance weight 0.286 ). However, this sub-region can develop in a natural way, and any non-stimulated activity will further improve its appeal.

For the second sub-region, the most appropriate scenario turns out to be the agribusiness development scenario (importance weight 0.317). The principal activity here would be to create an effective agricultural sector (competitive on the domestic market) and modernising the food processing industry. These activities require significant intensification (task importance weights greater than 10 points).

The third sub-region requires the promotion of a multi-functional development by supporting industry and services (importance weight 0.345 ). The potential of cities with developed industry and gminas (smallest local authority units) located close to important transport links are advantageous for the development of industry and services. What hinders development in these areas is the generally low level of labour qualifications, so at present only industries and services which do not require highly qualified

\footnotetext{
* Research financed by KBN (Committee for Scientific Research, Poland)
} 
employees can be located here. Such businesses include construction (roads, houses, commercial buildings) and transport, and among services - restaurants.

The fourth sub-region appears to possess characteristics that make it suitable for the development of tourism and rural tourism (particularly seasonal holidays). These types of business would take advantage of its natural beauty (forests, lakes, historic landscapes). Here, the most important activities (more than 10 points) are tourism and natural protection. The specific character of these rural areas is confirmed by the scenario selected for them: multi-functional development including tourism and farm tourism (importance weight 0.335 ).

What is notable in sub-region $\mathrm{V}$ is the relatively large number of tasks that should be implemented with a high intensity (more than 10 points). This stems from the poor development of these areas. Consequently, the following tasks are deemed to be very important: unemployment reduction, education, industry and services, sanitation and nature protection. This sub-region requires multi-functional development through supporting non-farm activities (importance weight 0.343 ).

The last sub-region should develop taking advantage of its rich forests (importance weight 0.485). Rich forest resources offer opportunities for developing rural tourism as well as wood and forestry product processing. Additional assets for developing rural tourism include: the appealing land relief, presence of historic landscapes, preserved elements of folk culture and some tourist infrastructure. The essence of all activities in these areas is to reduce unemployment and improve quality of life by intensifying and modernising their economic development.

Saaty's method facilitates the selection of the best rural area development scenario (from all those proposed), because the selection is made by comparing the importance of every pair of strategic objectives for rural area development and of every pair of activities supporting this development. This is in contrast to the classical approach to scenario-writing, where the intuition and personal preferences of scenario authors play a greater role. 